\title{
Dimensions of Learning: Adults Watching the Youth TV Series "Skam"
}

\author{
Jannike Vik, Christin Tønseth \\ Email address: \\ jannikevik@gmail.com (J. Vik), christin.tonseth@ntnu.no (C. Tønseth) \\ ${ }^{*}$ Corresponding author
}

Department of Education and Lifelong Learning, Norwegian University of Science and Technology, Trondheim, Norway

To cite this article:

Jannike Vik, Christin Tønseth. Dimensions of Learning: Adults Watching the Youth TV Series "Skam". International Journal of Education, Culture and Society. Vol. 4, No. 6, 2019, pp. 111-119. doi: 10.11648/j.ijecs.20190406.13

Received: November 5, 2019; Accepted: November 26, 2019; Published: December 11, 2019

\begin{abstract}
Formal, non-formal and informal learning all fall under the concept of lifelong learning. These refer to different contexts, processes and outcomes of learning. TV-watching, for instance, can be a learning context promoting both transformative learning and identity development. Many adults were enthusiastic about watching the Norwegian TV youth series "Skam" (Shame), which was originally intended for youths between the ages of 15 to 16 . We found it interesting that adults watched the series and wanted to find out what and how adults can learn from watching an entertainment program on TV, through a qualitative study. Seven adult informants aged between 30 and 55 years participated in the study. All of them watched the first seasons of "Skam" on TV. The analysis is structured around Illeris' three-dimensional learning model. When adults watch something recognizable and emotionally engaging on TV, they can learn because their interest and motivation increases. The increased insight and awareness in form of a transformative learning process can lead to both identity development and attitudinal changes in adults. The best learning outcomes for adults appear through communication and reflection with others about what they have seen.
\end{abstract}

Keywords: Informal Learning, Adult Learning, TV Series, Transformative Learning, Identity, Dimensions of Learning

\section{Introduction}

The term 'lifelong learning' suggests that people have not finished learning even when they have completed a formal education. The notion that learning occurs primarily at school is widespread, despite the attention that has been devoted to informal learning in recent years. Formal, non-formal and informal learning all fall under the concept of lifelong learning. These refer to different contexts, processes and outcomes of learning. Together, they suggest that people can learn regardless of where they are, how old they are and what they are doing. For example, they can learn while watching $\mathrm{TV}$ in their own living rooms [1-3].

When people learn through watching TV and movies, they learn in an informal fashion. Informal learning is often referred to as everyday learning, casual learning, self-directed learning or 'danning' [4]. People can learn without any intention of doing so, and they can do so in contexts in which learning is not the primary goal.

Informal learning also refers to the learning process; it can be random, planned, self-directed or interest-based [5]. We live in a media-dominated society in which the media is one of the most important arenas for learning. The media is not just a reflection of what occurs in a culture, as it also contributes to cultural creation and raises people's awareness of different themes [6]. By raising questions about how informal learning occurs through media and TV, knowledge concerning the learning process in general can be increased. This means becoming aware of the potential that may lie in informal learning. Additional knowledge could help to improve the organization and facilitation of adult learning in various forms and contexts. This article aims to explore informal learning among adult viewers of the Norwegian TV series Skam. The article seeks to answer the following question: In what way do adults experience learning through watching the TV series Skam?

\section{The TV Series Skam}

Wright and Sandlin [7] studied what female viewers learned 
from the early 1960s TV series The Avengers. Wright and Sandlin claim that their study indicated that transformative and lifelong learning can take place in people's living rooms.

Transformative learning is a type of restructuring and pervasive learning that can change both people's identities and philosophies of life [4]. Wright and Sandlin's study inspired our own research, which focuses on adult learning through watching the Norwegian TV series Skam. Many adults were enthusiastic watching this youth series, which was originally intended for youths between the ages of 15 to 16 . It was interesting that adults watched the series, as it became increasingly popular and was consistently featured in the news For this reason, we thought that this series could have a similar potential for learning as did The Avengers in the 1960s. Skam was aired over four seasons, running from autumn 2015 to spring 2017. The series took the form of short episodes of various durations that were aired almost every day. Episodes consisted of communication in the form of text messages and movie clips about different situations or scenes from young people's everyday lives, at school, home or other venues. Every Friday night, all the week's episodes were broadcasted on TV. The week's episodes were simultaneously released on the TV channel's website.

\section{Rediscovering Informal Learning}

Unplanned and random forms of learning are usually referred to as 'informal'. Some of the characteristics of these forms of learning includes restrictions regarding the use of time, few specific expectations about concrete learning outcomes, a lack of certifications and the fact that learning occurs as a 'side effect' of other goals. Informal learning describes the everyday learning and development of new knowledge [8].

Informal learning should no longer be regarded as an inferior form of learning whose main purpose is to act as the precursor of formal learning; it needs to be seen as fundamental, necessary and valuable in its own right, at times directly relevant to employment and at other times not relevant at all. [9].

Researchers and commentators in the adult education and lifelong learning field have demonstrated an increased interest in informal learning. Bentley [10] examined 'learning beyond the classroom', Coffield [9] 'the necessity of informal learning', Marsick and Watkins [11] and Dale and Bell [12] 'informal and incidental learning in the workplace' and McGiveney [13] 'informal learning in the community'. However, this interest has not been reflected to any significant extent in policy statements and reviews. Coffield [9] claims that the focus remains on formal provision, qualifications and accountability.

The central and defining feature of informal learning is the learning context. The learning context of this article is watching TV - more precisely, the Norwegian TV series Skam.

\section{TV and Film as Learning Contexts}

Recent research in the field of adult learning suggests that adults learn a significant amount through watching TV [14-25]. For example, research indicates that adult learners partially construct their identity by identifying with characters whom they can relate their own experience to. Through TV, viewers are exposed to different ideologies, values, and behaviors which they can choose to incorporate into their own lives [25].

Giroux [26] argues that films are forms of public pedagogy and that pleasure is a significant factor in their pedagogical efficacy: 'They deploy power through the important role they play connecting the production of pleasure and meaning with the mechanisms and practices of powerful teaching machines' [26]. Giroux argues that TV offers more space and requires more attention because it cannot be a backdrop to other activities, such as completing household chores [27]. Long-running TV series, which this paper focuses on, feature extended story arcs, develop complex characters and are part of their audience's lives for much longer than films [27]. They offer the opportunity for individuals to engage with characters over an extended period. There is also ample evidence of extensive, passionate dialogue between viewers on websites dedicated to favorite TV programs and of creative imaginative work in the form of 'slash' fiction by fans. This is also something that Jarvis and Burr [27] emphasized.

Whilst TV viewing may be interrupted or combined with other activities, this can serve to integrate watching TV series more fully into individuals' lives. Adults in diverse learning situations constitute heterogeneous groups with varying experiences, values, attitudes, conditions and assumptions. These differences represent both resources and limitations when it comes to learning. Adults who follow the same TV series are also a heterogeneous group of viewers, who share the common interest of watching the same series.

If adults are to learn something through watching a TV series, some of the well-known educational principles in adult learning must be taken into consideration. For example, the principle of personalized education concerns considering an individual participant's needs and prerequisites. Customized training focuses on creating wellbeing, mastering feelings and encouraging a sense of belonging, all of which make learning more effective [28-29]. Modern andragogy emphasizes the importance of linking a subject to participants' experiences and realities [30]. Knowles argues that associating the familiar with the unknown is a prerequisite for understanding, seeing relationships and forming meaning [30]. In 'assimilative learning', new knowledge is added to existing knowledge. 'Accommodative learning', in contrast, involves the restructuring of existing knowledge in one or more mental forms and requires more energy from the learner. 'Accommodative learning' also includes transformational learning, which is described as learning that involves changes in a learner's identity [31-32]. Dialogue and reflection are emphasized as important tools for linking past experiences and knowledge with new impressions and new knowledge. Dialogue can also build bridges between people and enable communication and reflection [33]. Modern andragogy also stresses that adults are self-governing in their approach to 
learning and have a fundamental need to be treated as independent and self-responsible [32].

To sum up, principles of walking from the familiar to the unknown, the use of dialogue and reflection and self-directed learning are among the important educational principles in adult learning. It may be difficult to identify these principles in situations where people are watching TV series, as this is not a planned and organized classical learning situation. In addition, the learning does not take place in a learning environment wherein one can reflect together with a facilitating teacher and classmates.

\section{Illeris' Three Learning Dimensions}

Illeris' definition of learning is broad: 'Learning can be understood as a change over time'. He states that learning includes 'any process within individuals that leads to a lasting capacity change' [4]. Learning requires two simultaneous and very different processes: social and individual acquisition processes. These processes form the framework of Illeris three-dimensional learning model, which describes three dimensions that are fundamental to all learning: content, driving force and interaction. We have chosen to use a different order than Illeris in this paper, starting with the driving force dimension, as we consider the driving force as a kind of starting point and the basis for the acquisition of content.

The driving force dimension includes emotions as an important component. Emotions can be described as different mental conditions, including joy, anger, fear, sadness and disgust [34]. In this article, the term 'feelings' is used to describe the more light-hearted emotions experienced when something likeable and interesting is seen. The driving force dimension also includes mobilizing the energy required to learn something. Curiosity or necessity may provide the motivation to seek new knowledge, new understanding or skills. Motivation, feelings and will are important components of the driving force dimension.

The 'content dimension' refers to what is learned. It does not make sense to talk about learning without content. Content can be knowledge, skills, insights and attitudes and may take the form of identification and recognition of one's own experiences.

The third dimension refers to the interaction between the social and material world. It is referred to as the interaction dimension' and concerns socialization and integration in a community. The signal words that Illeris emphasizes for the interaction dimension are action, communication and cooperation [4].

\section{Transformative Learning and Identity}

Transformative learning theory is concerned with adults' potential for development and perspective-change through self-management and critical reflection. According to Transformative learning theory, adults reflect on situations, occurrences and things that happen to them and senses. Through these reflections, adults can change their understanding of the world and their lives. The basic hypothesis is that transformation is an extensive and demanding process in which an adult becomes conscious of his or her own values, meanings, attitudes and actions and aware of the fact that these are socially constructed. By critically reflecting on themselves and their own lives, adults can become motivated to adopt new ways of living [35-36]. Illeris outlines three prerequisites for transformative learning: relevant schemes that can be changed or restructured must exist; there must be an interest or need to mobilize enough energy for this process; and the learner must feel sufficiently confident to be able to let go of the well-known and established [4].

In addition to Illeris' three requirements, we add empathy as a further prerequisite for transformative learning. When a person participates in the lives of others, for example by watching $\mathrm{TV}$, emotional connections to his or her own experience can be created. Jarvis [37] defines empathy as the ability to share the experiences and feelings of others and to develop an understanding of their perspectives and worldviews. Engaging with TV series has the potential to initiate transformative learning because it induces intense vicarious experience. This enables people to accelerate the learning that may occur through ordinary lived experiences. In this way, a series can become the 'disorienting dilemma' or the 'trigger' for transformation [38].

The concept of transformative learning includes all learning that implies changes in the identity of the learner [32]. Identity can be described as mental structures that define how people perceive themselves and how they are perceived by others. Identity can be created, developed and changed through learning [4, 31]. Illeris designed a model inspired by, and based on, the personality and stage models of Freud, Piaget and Erikson [31]. At the center of the model is the core identity, also referred to as the self-identity. This is the most basic layer in the identity structure and concerns the experience of being the same person in different situations over time. The core identity is maintained continuously, but it can still be developed and changed through learning. Typical changes in core identity tend to happen slowly and almost without being noticed. Transformative learning can lead to sudden changes in this identity layer. Outside the core identity, Illeris places the personality layer, which includes how people like to be perceived by others, their attitudes, values, opinions, communication habits, and degree of social appeal. This is a relatively stable condition but is more susceptible to changes than the core identity.

Outside the relatively stable identity core and the more flexible personality layer, Illeris places what he refers to as 'the more labile preference layer'. This layer includes how one might address both minor and major problems, important routines, and how one should behave in various everyday situations. These conditions are more open to change if such a change does not conflict with the core identity or personality layer [31]. From this description, we can formulate the simplified assumption that, while transformative learning can lead to changes in the core identity and personality layer, assimilative learning can lead to additions to the preference layer. 


\section{Method}

This study employs a qualitative approach, as it places greater emphasis on understanding and depth rather than explanation and propagation. Such an approach also implies closer proximity to the data and interactions with the informants. A semi structured interview guide was used in the interviews, and themes and questions were formulated in advance. The formulations were not defined in detail, nor were the order of the themes. Semi-structured interviews are often referred to as a 'conversation with specific intentions' [39] or as in-depth interviews with semi-solid structures [40]. The questions were structured around Illeris' three dimensions of learning: driving force, content and interaction.

The informants were recruited through social media. Four women and three men between the ages of 30 and 55 agreed to participate in the half hour interviews. It can be difficult to determine how many informants are required before beginning a survey. Seidman argues that two criteria are important when selecting interviewees for qualitative research: First, the selection must reflect a width among the informants about what is being investigated. Second, it should provide enough information and ensure that one can reach a saturation point [39]. The informants in our study were sufficiently distinct from each other that there was not much repeated or redundant information. The following statement by one of the informants inspired us to find pseudonyms for the adults in the survey:

"Most people go to the theatre in order to see a piece from Ibsen. I would rather be at home watching the last episode of Skam!" (Hedda, 55 years old).

We assigned all our informants pseudonyms derived from the characters of Norwegian author Henrik Ibsen; these names have no intentional similarity to the actual names, personal characteristics or age of the informants. The following is a brief description of the seven informants.

'Aase' is a single, 40-year-old woman without children. She holds a master's degree in health science and works part-time in a service industry while seeking employment. Aase watches $\mathrm{TV}$ every day and uses it as a form of relaxation in the evenings. She began to watch Skam out of curiosity.

'Hedvig' is 35 years old and married with children. She holds a bachelor's degree and engages in social work. She is currently pursuing further education. She says that she does not watch TV frequently on weekdays but that she does so more often on weekends. She heard about Skam from someone she trusted and decided to give the series a chance.

'Eyolf' is 30 years old and in a domestic partnership. He has a trade certificate in a craft and is co-owner of a small business. Eyolf says that he does not spend many hours in front of the TV every day but likes relaxing before bedtime. One of his friends recommended Skam.

'Torvald' is 49 years old, a father of two and lives with the mother of his children. He watches a great deal of TV every day but rarely in 'real time'. He holds a bachelor's degree and works with youth and politics. Torvald has watched Skam since the beginning, and he is the only member of the sample who thought in advance that he could learn something from the program.

'Peer' is also a father of two, 54 years old and lives with the mother of his (adult) children. He works with youth and child welfare. Peer has college education in health science. He is a moderate TV viewer. Peer began watching Skam because he was curious, and he was surprised by how addictive the series was.

'Fanny' is mother of two small kids and is in a domestic relationship with her children's father. In addition to the daily care of her children, Fanny works in health care as a nurse. As her everyday life is somewhat busy, she watches very little TV. She became curious about Skam when she heard about the series on the radio, and several of her friends started to follow the series as well.

'Hedda' is married and has three adult children. She is 55 years old. Hedda holds a master's degree and a management position in the public sector. She frequently travels for her job and is an active media user due to spending long periods of time alone in a commuter apartment away from her home. Hedda began to watch Skam out of curiosity and to stay informed on how young people live.

The data was processed using a thematic analytical approach. A thematic approach is characterized by focusing on the topics that are represented in a project. By studying the information provided by all a survey's participants, the researcher attempts to explore the themes that arise [41]. To be able to theorize the content or make a different degree of interpretation, it is necessary to have a certain distance from the material. Thagaard [41] recommends starting with the predefined topics in the problem, then developing categories that prove relevant during in the analysis process. In a subsequent review of the data, the informants' statements were introduced into a matrix, which was inspired by a stepwise deductive-inductive approach in the form of text-based coding. Such textual codes are not possible to set up before data generation, as this can only be done afterward with reference to the actual empirical data [40]. Switching between an inductive and a deductive approach repeatedly, as a result of which the constant movements between the whole and part lead to increased knowledge of the phenomenon being studied, is referred to as an abductive process or a hermeneutic circle [42].

The study's findings are structured around Illeris' three-dimensional learning model and are presented through three main categories: the driving force dimension, the content dimension and the interaction dimension.

\section{Analysis}

\subsection{The Driving Force Dimension}

The driving force dimension includes elements such as motivation, interest and emotion. The questions posed to the informants in this context was concerning their motives for watching Skam and the feelings that may have arisen when they have watched this series. Did they have any specific motive for watching the series, or was it random? They were also asked questions concerning what had prompted their interest and why they chose to continue watching the TV 
series. The driving force dimension includes two different factors: the informants' individual motivations for watching Skam and their motivation related to whom the informants want to be and appear.

Most of the informants indicated that they were curious for various reasons. Some of them had received advice from people whom they trusted, while other informants are parents themselves and wished to see what children and young people occupy themselves with. One of the informants, Torvald, has great deal of contact with young people in his job; in addition, he has two children who will soon become teenagers. He says he had heard of Skam and planned to watch the series because he wanted to obtain insight into what is happening in youths' everyday lives. Torvald stands out as the only informant in the sample who had a concrete and pronounced motive for viewing at Skam. Those informants who have daily contact with young people, either privately or in the context of their work or both, might have a personal and/or job-related interest in or motive to watch the TV series.

Some of the informants began to watch Skam after receiving tips from people whom they trusted, such as family and friends. A few of the informants expressed skeptical attitudes toward the series in advance, while most of others had a more positive attitude toward it. Only Torvald stated that he had a concrete motive for watching Skam, as the others were largely curious. The informants' interest in Skam was prompted by elements in the series that was surprising and new to them. One informant was also keen to stay abreast of what is new and popular and liked the series due to its quality. Watching Skam may not be consistent with popular notions of what adults choose to view. However, the content also broke with the expectations of one of the informants: 'I liked that it's a bit different. Like, the boys being good at school, while one of the girls is not quite so good... and it's breaking with the expectations many have... of girls being like more clever students maybe? So, it just caught my interest immediately, because it is something completely different.' (Peer)

Peer's experience may indicate something about how boys and girls are usually depicted on TV or what is "within the discourse'. Several of the informants mentioned, of their own initiative, that they thought it was exciting to watch a youth series and break with society's expectations of what adults should do. By following up on what is happening and being up to date regarding technological innovations, such as using tablets and mobile data to watch TV, they signal that they are staying abreast of new developments. In some social contexts, this can increase a person's status.

The informants emphasized that recognition and identification are important factors influencing their interest in watching TV programs. It may resemble something that one has experienced and thus can appear credible or true. For example, old feelings can be awakened, and a person can remember what it was like to be very young. Credibility and authenticity are described by the informants as some of the most important qualities of Skam. Hedvig states that it was very important to her that she could recognize her own, partly forgotten, emotions: 'It's almost like you can recognize the feeling of being in love, and yes, miss it a little... ah, to be young again!' (Hedvig).

Informants mentioned that they were addicted to the series in some way. To be hooked, or addicted, is mentioned by all the informants. They stated that they liked the excitement and atmosphere in Skam and described themselves as having become emotionally engaged. As a result, they often neglected other activities in favor of watching the series. The driving force to keep track of the series was strong.

\subsection{The Content Dimension}

The content dimension is mainly concerned with the learning outcome. Outcomes may include knowledge, understanding, reflections and learning experiences. What do adults learn from Skam? During the interviews, the informants were asked whether they had gained insight into something they did not know before, concrete knowledge about different topics, whether they had an impression of an underlying theme or message and whether they had changed their opinion about something. How individual informants define learning varies.

Several informants express their understanding of learning as fact-based and leading to concrete knowledge of one or more topics. Both Aase and Peer mentioned that they gained insight into the language of youths. They also spent time determining what new words they had heard through the series meant. They were inspired to seek more knowledge concerning something they were not familiar with before watching the TV series. Fanny mentions reflection as a prerequisite for learning. She explains that she had an experience of learning something new through a discussion that two characters engaged in one of the episodes of Skam. The discussion was about conflict, violence and war, and Fanny states that 'I learned something new! I have just had the story presented earlier, not reflected on... how it, of course, has been useful to fight for the values we have today' (Fanny).

Torvald reports that the topics addressed in Skam changed his thinking slightly. He says that he has learned that he must become even better at listening to his children: 'I think that, by watching Skam, I get a bit more enlightened ... about a world that might be a bit closed to us parents' (Torvald).

Both Torvald and Hedda say that they have learned a great deal about today's youth in a positive manner by watching Skam. The new understanding entails a desire to act differently - to become a better listener, demonstrate more patience to youth and deal with young people in a more tolerant manner. In addition, they highlight the importance of being aware of young people today, including what they are thinking and the importance of communicating with them in a positive and tolerant manner. Several informants thus understand learning as involving greater insight and awareness. Hedvig says, however, that she is uncertain as to whether she has really gained new knowledge by watching Skam. She reports that she found the series entertaining and exciting and that it provided her with both a look back to her own youth and insight into today's youth culture; however, she is somewhat careful when it comes to defining this as learning: 
'I think, in a way, that I have a good insight into how youngsters are, so I have not learned so much about that. I also think I have a pretty good overview of the youth culture. I do not know if I have changed so much either in terms of attitudes or values.' (Hedvig)

Here, Hedvig communicates something about what she perceives as learning, namely changes in attitudes and values. She also says that Skam has helped to provide her with insight into youth culture and to 'feel what it was like to be young', including reflecting on her own experiences. Hedvig describes a learning outcome, but, at the same time, she says she does not necessarily regard this as new knowledge.

In Skam, each season focuses on different topics. The third season had homosexuality as a main theme. Several of the informants had thoughts about this, and the season made a strong impression. Aase found that the youngsters in Skam provided good examples through the way they responded to their friend Isak when he confided in them that he was gay. For both Torvald and Fanny, the series' stance on homosexuality changed their personal views on the subject. Torvald states that he was surprised by how natural it was for him to see gay infatuation and love depicted on TV. He says that, because of this, he would no longer be dismayed if his own son told him that he was gay. Torvald has thus experienced a significant change in his worldview. The informants emphasized that the way a theme such as homosexuality is presented in Skam can contribute to increased understanding both on the individual and community levels. They thus find that a program such as Skam can have a major impact.

The informants perceived several types of messages in Skam. Hedvig believes that the dissemination of positive messages and values is a conscious decision on the part of the makers of the series. She suspects that the TV series is not only designed to entertain. Equality, openness, and acceptance of inequalities in terms of worldview and religion are highlighted by the informants as messages and values they have noticed in the series. Peer found important topics highlighted in the relationships between the youngsters in the series and believes that this is something that adults could and should learn from. Hedda says she perceived 'tolerance' as a key theme in the main messages conveyed in Skam. She explained that there was tolerance for difference and a generosity and acceptance associated with people who are different or think differently. Peer and Torvald feel that it is good that Skam does not appear to have a moralizing intention or to be 'educational TV'. Torvald says 'That's so good ... that they can raise such a theme... which in some way can teach you a little, without making you feel you are being taught!' (Torvald). 'Being taught' is not considered desirable by all adults. Both Peer and Torvald state they like to learn, but learning does not have to be the intention of those who have made the series. Educational TV can be experienced as a little 'upside down' for adults. However, by illuminating taboos in the manner that Skam does, one can still influence people to think differently and inspire them to change their own attitudes: 'Maybe you are being inspired to get a bit tougher? Maybe give a little more fuck? Yes. I think they are very tough.
And... I like that!' (Eyolf).

All the informants report that they understand the underlying messages in the series, that they consider these messages to be positive and that these messages prompted thoughts and reflections on their part.

\subsection{The Interaction Dimension}

Learning constantly occurs in our interactions with our surroundings on the individual, group and social levels. The keywords for the interaction dimension are communication, relation and collaboration, and the research question for this section is as follows: What is the significance of the interaction dimension of learning? The informants were asked to what extent they had communicated with others about what they had seen and if this had any significance for them in terms of continuing to watch Skam. They were also asked if their relationships with people around them were in any way were influenced by the fact that they had watched Skam. We were interested in the meaning of interactions on learning, and how learning can impact interaction.

Several of the informants mostly watched Skam alone for various reasons. Some wanted to watch the series alone, while others did not convince other family members to watch along with them. Fanny was one of those who ended up watching Skam in solitude; she reflected on why: 'My husband just didn't watch it together with me. Eventually it just became my thing, sitting on the net TV and... enjoying myself! I thought about why I did not include him. Maybe I felt that it was good for me then, just having this for myself?' (Fanny) She did, however, share her thoughts and reflections about what she saw with her husband. Fanny states that, if he was interested in listening to what she wanted to discuss about the series, it was not so bad that he did not watch Skam with her.

Although several of the informants watched Skam alone, they communicated with others about what they saw. Communication and reflection are connected, and reflection is necessary for learning. This means that interaction leads to learning. Some of the informants also thought that Skam has had a positive impact on their relationships with others, as their learning led to changes in their interactions. Some of the informants believed that Skam had a general impact on society through the positive messages that the series conveyed.

\section{Discussion}

The informants began to watch the popular Norwegian TV series Skam after receiving suggestions from people whom they trusted, such as family members and friends. Some of the informants were initially quite skeptical regarding this 'youth series', while others had more positive expectations. Only one of the informants reported a concrete and unique motive for following the series, as the others were largely curious. The informants' interest in watching Skam was stimulated by aspects of the series that was surprising and interesting. Some of the informants said they were keen to keep track of what was new and contemporary, while some said they liked Skam because they thought it was of a high level of quality. 
Some informants reported that they felt slightly 'naughty' as result of watching the series and laughed a little about this during the interview. Acting in a 'naughty' manner by violating social expectations can be associated with challenging one's own identity. However, being active and following what is popular can also express one's identity. The attitudes, values and habits that are communicated to others signal the personality layer of our identity [4, 31]. The informants saw something that was both consistent and inconsistent with the experiences of their own youth or their own children and adolescents, and this made them interested in seeing the series $[65,4,31]$. This is in accordance with motivational theorists who consider motivation to be a situation-based state that is triggered by values, experiences, self-assessment and expectations [44].

Motivation, feelings and will are important components in the driving force dimension. Illeris' driving force dimension includes mobilizing the energy required to learn something new [4]. Curiosity or necessity may serve as the motive to acquire new knowledge, new understanding or skills. While many adults wanted to know more about young people's lives in general, many of the informants also recognized feelings and situations from their own youth. When a person can identify with the characters portrayed in a series and get the feeling of taking part in the lives of others, emotional relationships are created within their experience. In modern andragogy, the importance of linking the subject to the participants' experience and reality is emphasized [30]. Knowles stated that associating the familiar with the unknown is a prerequisite for understanding, considering relationships and forming meaning [30]. In accordance with Jarvis [37], this means that understanding and empathy increase, and people become receptive to transformative learning.

All the informants said that they became emotionally engaged while watching Skam, and they described themselves as more or less 'hooked'. A characteristic of informal learning is the contextual [8]. The 'content dimension' refers to what is learned. Its contents can include knowledge, skills, insights and attitudes and may take the form of identification and recognition of one's own experiences [4].

When the informants described what they thought they had learned, some of them were uncertain as to whether they had learned anything at all. Learning outcomes are usually understood as factual knowledge and as leading to changes in attitudes and values. They did not learn facts beyond gaining additional knowledge of contemporary youths' language and lives. However, the informants reported having gained insight and becoming more conscious, of having 'awakened a little'. Aase and Peer were inspired to learn about something new, while others changed their views especially about youths.

All the informants believed that Skam conveyed important messages about good values, while some appreciated the fact that this TV series is not educational TV. Research indicates that adult learners partially construct their identities by identifying with characters whom they can relate their own experiences to. Through TV, viewers are also exposed to various ideologies, values and behavior, any of which they can choose to incorporate into their own lives [25]. The informants' learning can thus be said to be both 'assimilative', as new knowledge was added to their existing experiences, and 'accommodative', as learning was deeper and led to changes in their identity [31-32].

What is conveyed through movies and TV is not necessarily meant to teach anything [26]. Giroux emphasizes that hidden messages serve to recycle the dominant culture's interests [45]. As Illeris describes, a typical learning situation features phases that alternate between assimilation and transformation [4]. Mezirow states that critical reflection on previous assumptions can lead to transformative learning through changes in the meaning of mind and 'habit of mind' [46]. When transformative learning leads to changes in core identity - the innermost and most fundamental part of the identity - it is useful to have the ability to critically reflect on these changes, as described by Brookfield [47-48] and Tisdell [49]. The purpose of critical interpretation is to be aware of what (possibly hidden) messages one receives. Increased awareness and critical reflection are linked to transformative learning [49].

When people learn something about others, they can learn something about themselves by identifying with what they are looking at. Aarsand [50] and Foucault [51] indicate that the 'normal' versus the 'abnormal' is justified through visualization of the subject's positioning in the existing social order. By watching TV, people learn something about the attitudes and values they can or should have. When the friends of gay Isak treat him in a respectful manner, it seems to have a great impact for those who are looking. A scene in which Noora clashes with the boy she believes has abused her has a similar impact. Several of the informants discussed such scenes. Some also referred to changes in their own attitudes, values and philosophy of life as a result of what they have seen.

Transformative learning theory deals with adults' opportunities for development and perspective-change through self-management and critical reflection. According to transformative learning theory, adults reflect on the situations and occurrences that they experience and the things that they sense. Through these reflections, people can change their understanding of the world and their lives. The basic hypothesis is that transformation is an extensive and demanding process in which an adult becomes conscious of his or her own values, meanings, attitudes and actions and aware that they are socially constructed. By critically reflecting on themselves and their own lives, adults can be motivated to try new ways of living $[35,36,38]$.

The interaction dimension concerns interaction with the social and material world, including the close social level, and the overall social level. Although several of the informants watched Skam alone, they communicated with others about what they had seen. Communication and reflection are connected, and reflection is necessary for learning. This means that interaction leads to learning. Some of the informants also thought that Skam had a positive impact on their relationships with others. The dialogue can build bridges between people and facilitate communication and reflection [33]. This learning led to changes in their interactions with others. Some of the 
informants believed that Skam had influenced a large section of the society through the good messages conveyed. They had a common interest to talk about the series. This acted as social bounding that tied them closer together.

\section{Conclusion}

Lifelong learning implies that learning occurs continuously and in different arenas throughout life. Learning can just as easily take place in one's spare time at home, in the workplace or while studying for a course at school or university, regardless of one's age. By discussing the results of the survey against relevant theory, we have attempted to answer the question of 'In what way do adults experience learning by watching the TV series Skam?' We can conclude that Illeris' three dimensions of learning were present in our informants' experience of watching the TV series. They primarily learned because they were interested. Their interest and motivation were stimulated as they became emotionally engaged by the fact that the series depicted something recognizable - as parents to youths of the same age as the actors in the series and/or by remembering their own youth. Engagement and genuine interest were the driving forces for following the series. The informants reported that they gained insight and became more aware of both their own and others' lives by watching Skam. They also experienced a transformative learning process through which their identities developed, and their attitudes and behaviour changed. Such a learning outcome was clearly suggested by those who communicated and reflected with others who were also engaged in watching Skam. The findings indicate and confirm that informal learning by following TV series that are perceived as interesting and engaging has the potential to lead to extensive learning effects.

\section{References}

[1] Lindtner, S. S and Skarstein; D. (eds.) (2018). Dramaserien Skam: analytiske perspektiver og didaktiske muligheter. [The drama series 'Skam': analytical perspectives and didactic possibilities. Bergen: Fagbokforlaget.

[2] Kosenko, K. and Layboy, J. (2018). The Instructional Capacity of Reality Television: Learning Survival Strategies from Survival Shows. Athens Journal of Mass Media and Communications, 4 (3), pp. 193-202.

[3] Schuhen, M. and Neubauer, M. (2015). Economic education via consumer advice programs? Informal learning based on the example of the television help format 'Out of Debt'. Citizenship, Social and Economic Education, 14 (3) pp. 193-202.

[4] Illeris, K. (2012). Læring [Learning]. Oslo: Gyldendal Akademisk.

[5] Merriam, S. B., Caffarella, R. S. and Baumgartner, L. (2007). Learning in adulthood: a comprehensive guide. San Fransisco: Jossey-Bass.

[6] Alvermann, D. and Hagood, M. (2000). Critical media literacy: Research, theory and practice in "new times". Journal of
Educational Research, 93, pp. 193-205.

[7] Wright, R. R. \& Sandlin, J. A. (2009a). Cult TV, Hip Hop, Shape-Shifters, and Vampire Slayers. A Review of the Literature at the Intersection of Adult Education and popular Culture. Adult Education Quarterly, 59 (2), pp. 118-141.

[8] Malcolm, J., Hodkinson, P. and Colley, H. (2003). The interrelationships between informal and formal learning. Journal of Workplace Learning; 15 (7/8). pp. 313-318.

[9] Coffield, F. (2000). The Necessity of Informal Learning, Bristol: The Policy Press.

[10] Bentley, T. (1998). Learning beyond the Classroom: Education for a changing world, London: Routledge.

[11] Marsick, V. J. and Watkins, K. (1990). Informal and Incidental Learning in the Workplace, London and New York: Routledge.

[12] Dale, M. and Bell, J. (1999). Informal Learning in the Workplace. DfEE Research Report 134, London: Department for Education and Employment.

[13] McGiveney, V. (1999). Informal Learning in the Community. A trigger for change and development, Leicester: NIACE.

[14] Armstrong, P. (2000). All things bold and beautiful: Research adult learning through soaps. Proceedings of the 41st Annual Adult Education Research Conference. University of Columbia, Vancouver, Canada, pp. 16-20.

[15] Armstrong, P. (2005). Managing diversity in the workplace: Representations of difference in The Office. Proceedings of the Standing Conference on University Teaching and Research in the Education of Adults, University of Sussex. Sussex, United Kingdom.

[16] Rogers, E. E. (2002). Waiting to exhale. African American Women and Adult Learning through Movies. Paper, presented at the annual meeting of the Adult Education Research Conference (43d, Raleigh, NC), pp. 326-332.

[17] Sandlin, J. A. (2005). Spend smart, live rich? A critical analysis of the consumer education lifestyle magazine Budget Living and its readers' forums. Proceedings of the 46th Annual Adult Education Research Conference. Athens, Georgia (pp. 387-392).

[18] Tisdell, E. J. and Thompson, P. M. (2005). The role of pop culture and entertainment media in adult education practice. Proceedings of the 46th Annual Adult Education Research Conference. University of Georgia, Athens, Georgia, pp. 425-432.

[19] Tisdell, E. J. and Thompson, P. M. (2006). Crashing into pop culture in dealing with diversity: Adult education and critical media literacy about movies and television. Proceedings of the 47th Annual Adult Education Research Conference. University of Minnesota, Minneapolis-St. Paul, Minnesota, pp. 397-402.

[20] Tisdell, E. J. and Thompson, P. M. (2007). From a different angle: The role of pop culture in teaching for diversity and critical media literacy in adult education. International Journal of Lifelong Education, 26, pp. 351-673.

[21] Wright, R. R. (2006a). A different definition of boob-tube: What Dr. Catherine Gale, of The Avengers, taught women. Proceedings of the 36th Annual Adult Education Research Conference. University of Minnesota, Minneapolis. St. Paul, Minnesota, pp. 471-476. 
[22] Wright, R. R. (2006b). Popular culture, cult TV, and gender resistance: Informal learning from prime-time feminism. Proceedings of the 47th Annual Standing Conference on University Teaching and Research in the Education of Adults. All Saints College, Leeds, United Kingdom, pp. 449-464.

[23] Wright, R. R. (2007a). Learning empowerment, resistance and female identity development from popular television: Trans-women tell stories of trans-formation. Proceedings of the 48th Annual Adult Education Research Conference. Mt. Saint Vincent University, Nova Scotia, Canada, pp. 517-522.

[24] Wright, R. R. (2007b). The Avengers, public pedagogy and the development of British women's consciousness. In: Tisdell, E. J., Thompson, P. M. (Eds.) New directions in adult and continuing education: No. 115. Popular culture and adult education. San Fransisco: Jossey-Bass, pp. 63-73.

[25] Wright, R. R. and Sandlin, J. A. (2009a). Cult TV, Hip Hop, Shape-Shifters, and Vampire Slayers. A Review of the Literature at the Intersection of Adult Education and popular Culture. Adult Education Quarterly, 59 (2), pp. 118-141.

[26] Giroux, H. (2002). Breaking into the movies. Malden: MA, Blackwell.

[27] Jarvis, C. and Burr, V. (2012). The Transformative Potential of Popular Television: The Case of Buffy the Vampire Slayer. Journal of Transformative Education, 9 (3) pp. 165-182.

[28] Engen, T. O. (2010). Tilpasset opplæring: utkast til en faglig forståelse [Costumized training: draft to a professional understanding]. In: G. Berg \& K. Nes (Red.), Tilpasset opplæring-støtte til læring [Costumized training - learning support]. Vallset: Oplandske Bokforlag.

[29] Dysthe, O. (2007). The challenges in new assessments in a new culture. In: A. Havnes, and L. McDowell (Eds.), Balancing dilemmas in assessment and learning in contemporary education, pp. 15-32. New York: Routledge, Taylor \& Francis Group.

[30] Knowles, M. S. (1970). The Modern Practice of Adult Education: Andragogy versus Pedagogy. New York: Associated Press.

[31] Illeris, K. (2013). Transformativ læring \& identitet [Transformative learning \& identity]. Frederiksberg: Samfundslitteratur.

[32] Illeris, K. (2014). Transformative learning re-defined: as changes in elements of the identity. International Journal of Lifelong Education, 33 (5), pp. 573-586.

[33] Skrefsrud, T-A. (2012). Å være lærer i interkulturell kontekst. Om dialogens betydning for lærerkompetansen. [To be a teacher in an intercultural context - the meaning of dialogue to the teacher competence]. Trondheim: PhD thesis NTNU.

[34] Katzenelson, B. (2004). Drivkræfter, følelser og erkendelse. [Driving forces, emotion and cognition]. København: Hans Reitzel.

[35] Mezirow, J. and Marsick, V. (1978). Education for Perspective Transformation. New York: Center for Adult Education.
[36] Mezirow, J. (2005). At lære at tænke som en voksen. [Learning to think like an Adult]. In: K. Illeris og S. Berri (red.): Tekster om voksenlæring [Teksts about Adult learning]. København: Roskilde Universitetsforlag.

[37] Jarvis, C. (2012). Fiction, empathy and lifelong learning. International Journal of Lifelong learning, 31 (6), pp. 743-758.

[38] Mezirow, J. (2000). Learning as transformation: critical perspectives on a theory in progress. San Fransisco: Jossey-Bass.

[39] Ryen, A. (2012). Det kvalitative intervjuet. Fra vitenskapsteori til feltarbeid. [The Qualitative interview. From science theory to fieldwork]. Bergen: Fagbokforlaget, p. 99.

[40] Tjora, A. (2012). Kvalitative forskningsmetoder i praksis. [Qualitative research methods in practice]. Oslo: Gyldendal Akademisk.

[41] Thagaard, T. (2013). Systematikk og innlevelse. En innføring i kvalitativ metode. [Systematics and immersion. An introduction to qualitative methods]. 4. utg. Bergen: Fagbokforlaget.

[42] Johannessen, A., Tufte, P. A. and Christoffersen, L. (2011). Introduksjon til samfunnsvitenskapelig metode. [Introduction to the method in social science]. Oslo: Abstrakt forlag AS.

[43] Jarvis, P. (2006). Towards a Comprehensive Theory of Human Learning. London: Routledge.

[44] Skaalvik, E. and Skaalvik, S. (2005). Skolen som læringsarena: selvoppfatning, motivasjon og læring. [The school as Learning arena: self-perception, motivation and learning]. Oslo: Universitetsforlaget.

[45] Sandlin, J. A., Wright, R. R. and Clark, C. (2011). Reexamining Theories of Adult Learning and Adult Development Through the Lenses of Public Pedagogy. Adult Education Quarterly, 63 (1), pp. 3-23.

[46] Mezirow, J. (2003). Transformative learning as discourse. Journal of transformative education, 1 (1), pp. 58-63.

[47] Brookfield, S. D. (1987). Developing critical thinkers: challenging adults to explore alternative ways of thinking and acting. San Francisco: Jossey Bass.

[48] Brookfield, S. D. (2000). Transformative Learning as Ideology Critique. In: J. Mezirow et al. Learning as Transformation Critical perspectives on a Theory in progress. San Franscisco: Jossey-Bass.

[49] Tisdell, E. J. (2008). Critical Media Literacy and Transformative Learning Drawing on Pop Culture and Entertainment Media in Teaching for Diversity in Adult Higher Education. Journal of Transformative Education Volume, 6 (1), pp. 48-67.

[50] Aarsand, L. A. (2011). Parents, expertise and identity work: the media conceptualized as a lifelong learning practice. Pedagogy, Culture \& Society, 19 (3), pp. 435-455.

[51] Foucault, M. (1970). Diskursens orden. [The Discourse order]. Oslo: Spartacus Forlag AS. 